\title{
Quitosana e adjuvantes para o controle preventivo do mofo azul da macieira
}

\author{
Bruno S. Canaver \& Robson M. Di Piero \\ Departamento de Fitotecnia, Centro de Ciências Agrárias, Universidade Federal de Santa Catarina, 88040-900, Florianópolis, \\ $\mathrm{SC}$, Brasil
}

Autor para correspondência: Robson M. Di Piero, e-mail: robson@cca.ufsc.br

\begin{abstract}
RESUMO
A eficiência de formulações contendo quitosana e os adjuvantes glicerol, sorbitol, oleato de sorbitano, Tween 80 ou estearato de magnésio foi avaliada para o controle do mofo azul em frutos de macieira. Maçãs da cv. Fuji foram desinfestados, feridos e imersos por três minutos nas suspensões. Após a secagem do revestimento por $2 \mathrm{~h}$, os frutos foram inoculados com Penicillium expansum e armazenados, sob alta umidade relativa, a $25 \pm 1^{\circ} \mathrm{C}$. Avaliou-se, periodicamente, a severidade da podridão e a incidência aos 16 dias após a inoculação. A incidência do mofo azul em frutos imersos em quitosana foi reduzida em, aproximadamente, $40 \%$. Houve uma redução de $53 \%$ e $72 \%$, em média, na severidade observada em frutos imersos em quitosana a $0,25 \%$ e $0,5 \%$, respectivamente, quando comparado às testemunhas. Dentre as formulações, a que continha quitosana a $0,5 \%$, estearato de magnésio a $0,3 \%$ e Tween 80 a $0,1 \%$ mostrou-se a mais promissora para o controle do mofo azul, reduzindo em 75\% a incidência e em 97,7\% a severidade da podridão. A adição dos adjuvantes sorbitol e oleato de sorbitano à suspensão de quitosana não contribuiu para aumentar significativamente os níveis de controle da podridão.

Palavras-chave: Malus domestica, Penicillium expansum, pós-colheita, revestimentos.
\end{abstract}

\begin{abstract}
Chitosan and adjuvants for the control of blue mold in apples

The efficiency of formulations containing chitosan and the adjuvants glycerol, sorbitol, sorbitan oleate, Tween 80 and magnesium stearate was evaluated for the control of blue mold in apple fruits. Apples of cv. Fuji were disinfested, wounded and immersed for 3 minutes in the suspensions. After drying for $2 \mathrm{~h}$, fruits were inoculated with Penicillium expansum and stored under high relative humidity, at $25 \pm 1{ }^{\circ} \mathrm{C}$. The disease severity was evaluated periodically and the blue mold incidence was measured at 16 days after inoculation. The blue mold incidence in fruits immersed in chitosan was reduced by around $40 \%$. On average, a reduction of $53 \%$ and $72 \%$ in severity was observed on fruits immersed in chitosan at $0.25 \%$ and $0.5 \%$, respectively, compared to the control. Among the formulations, the one containing chitosan $0.5 \%$, magnesium stearate $0.3 \%$ and Tween $800.1 \%$ was the most promising for controlling blue mold. It reduced the decay incidence in $75 \%$ and the disease severity in $97,7 \%$. The addition of adjuvants sorbitol and sorbitan oleate to the chitosan suspension has not contributed significantly to increase the levels of decay control.
\end{abstract}

Key words: Malus domestica, Penicillium expansum, coatings, post-harvest.

A cultura da macieira no Brasil abrange uma área de pomares em produção de, aproximadamente, 38.500 ha, distribuídos, principalmente, pelos estados de Santa Catarina (20.014 ha), Rio Grande do Sul (16.293 ha) e Paraná (2.110 ha). A produção nacional foi de 1.276 mil toneladas de frutos na safra 2009/10 (IBGE, 2011).

No período pós-colheita, comumente é possível observar danos em frutos que não são manipulados adequadamente durante a colheita, no transporte ou na seleção, bem como em frutos que não são tratados com inibidores microbianos eficientes (Sanhueza, 2004). Neste período, danos causados por Penicillium expansum (Link.) Thom, principal agente causal do mofo azul, são comuns (Baert et al., 2008). Esse fungo encontra-se difundido em todas as regiões produtoras de pomáceas, podendo causar perdas de 0,5 a $3 \%$ nos frutos armazenados sob refrigeração, mesmo quando utilizadas todas as recomendações de manejo (Sanhueza, 1996; Sanhueza, 2004). Os esporos podem permanecer viáveis, de uma safra para outra, em sacolas de colheita, caixas de madeira e nas câmaras de armazenamento (Sanhueza, 2004).

O controle pós-colheita de doenças em maçãs, geralmente, é obtido pela imersão dos frutos em soluções saneantes, como hipoclorito de sódio ou dióxido de cloro (EMBRAPA, 2011), ou em fungicidas, como iprodione ou imazalil (MAPA, 2011). Entretanto, a preocupação dos consumidores e exportadores quanto à presença de resíduos de agrotóxicos em produtos agrícolas e o acúmulo dessas substâncias no ambiente têm estimulado a busca por métodos alternativos de controle de doenças.

Opolímero de ocorrência natural quitosana, obtidoem escala industrial a partir da deacetilação alcalina da quitina, apresenta propriedades biológicas, como baixa toxicidade, biodegradabilidade, biocompatibilidade, além de apresentar 
efeito antifúngico ou induzir respostas de defesa em frutos tratados (Romanazzi et al., 2002; Camili et al., 2007; Dutta et al., 2009). Revestimentos à base de quitosana apresentam potencial para controlar perdas causadas por podridões póscolheita e para prolongar o tempo de armazenamento de frutos (El Ghaouth et al., 1992; Romanazzi et al., 2002), especialmente quando combinados com outros agentes antimicrobianos (Zivanovic et al., 2005) ou adjuvantes que melhoram as características físicas das formulações (Kim et al., 2006), aumentando a capacidade da suspensão se dispersar homogeneamente sobre a superfície revestida.

Desse modo, o objetivo do presente trabalho foi avaliar o efeito preventivo da imersão de frutos de macieira cv. Fuji em suspensões de quitosana, contendo ou não os adjuvantes glicerol, sorbitol, Tween 80 , oleato de sorbitano ou estearato de magnésio, para o controle do mofo azul.

O fungo $P$. expansum, cedido pela Dra. Rosa Maria Valdebenito-Sanhueza, foi isolado de fruto sintomático de maçã e crescido em placas de Petri contendo meio de cultura Batata-Dextrose-Ágar (BDA), mantidas em sala de crescimento a $25 \pm 1{ }^{\circ} \mathrm{C}$, sob luz fluorescente e fotoperíodo de $12 \mathrm{~h}$. Frequentemente, o fitopatógeno foi reinoculado e reisolado de frutos sintomáticos para manter a patogenicidade. As suspensões de esporos foram obtidas de colônias crescidas em BDA durante sete dias, utilizando-se água destilada, e a concentração ajustada para $10^{5}$ conídios $\mathrm{mL}^{-1}$ em câmara de Neubauer.

A quitosana utilizada apresentava $85 \%$ de deacetilação e foi fornecida pela Empresa $\mathrm{AD}$ Oceanum Indústria e Comércio Ltda. (Governador Celso Ramos, SC). As suspensões foram preparadas conforme Felipini \& Di Piero (2009), utilizando-se $\mathrm{HCl}$ 0,05 M como solvente e ajustando o pH final de cada suspensão para 5,6 com a adição de $\mathrm{NaOH} 2 \mathrm{M}$.

Maçãs da cultivar Fuji, pertencentes à Classe $120 \mathrm{e}$ Categoria CAT1, foram cedidos pela Cooperativa Regional Agropecuária Serrana (Cooperserra), sediada em São Joaquim, SC. Previamente aos experimentos, os frutos foram imersos em solução de hipoclorito de sódio $(0,025 \%$ cloro ativo) durante 2 minutos, lavados em água corrente e secos ao ar, em temperatura ambiente.

Para avaliar o efeito protetor das formulações de quitosana contra o mofo azul foram realizados quatro experimentos. No primeiro, as maçãs foram feridas com agulha de $1 \mathrm{~mm}$ de diâmetro, com perfurações de $5 \mathrm{~mm}$ de profundidade em dois locais distantes $2,5 \mathrm{~cm}$ entre si, na região equatorial e, posteriormente, imersos por três minutos nas seguintes suspensões: I) quitosana a $0,25 \%(\mathrm{~m} / \mathrm{v})$; II) quitosana a $0,25 \%$ com Tween 80 a $0,1 \%(\mathrm{v} / \mathrm{v})$; III) quitosana $0,25 \%$ com Tween $800,1 \%$ e estearato de magnésio a $0,1 \%$ $(\mathrm{m} / \mathrm{v}) ; \mathrm{IV})$ quitosana a $0,25 \%$ com glicerol a $0,25 \%(\mathrm{v} / \mathrm{v})$; V) quitosana a $0,25 \%$ com glicerol a $0,25 \%$ e Tween 80 a $0,1 \%$; VI) quitosana a $0,25 \%$ com glicerol a $0,75 \%$. Após a secagem por $2 \mathrm{~h}$, os frutos, posicionados com os ferimentos voltados para cima, foram inoculados com $25 \mu \mathrm{L}$ de suspensão de esporos de $P$. expansum $\left(10^{5}\right.$ conídios $\left.\mathrm{mL}^{-1}\right)$, depositados nos locais de ferimento. Os frutos foram armazenados no interior de bandejas plásticas (400 x $270 \times 133 \mathrm{~mm})$ fechadas, sob alta umidade relativa, incubadas em sala de crescimento a $25 \pm 1{ }^{\circ} \mathrm{C}$. Como tratamento controle foram utilizados frutos imersos em água destilada e inoculados. $\mathrm{O}$ delineamento experimental foi inteiramente casualizado, com quatro repetições. Cada unidade experimental foi composta por uma bandeja contendo quatro frutos. Avaliouse a severidade da podridão medindo-se o diâmetro das lesões a cada quatro dias, realizando-se leituras em sentidos ortogonais com o auxílio de uma régua. A partir do valor médio do diâmetro das lesões ao longo do tempo, em cada repetição, calculou-se a área abaixo da curva de progresso da doença (AACPD), conforme Shaner \& Finney (1977): AACPD $=\sum\left[\left(\mathrm{y}_{\mathrm{i}}+\mathrm{y}_{\mathrm{i}+1}\right) / 2 \mathrm{x}\left(\mathrm{t}_{\mathrm{i}+1}-\mathrm{t}_{\mathrm{i}}\right)\right]$, em que $\mathrm{y}_{\mathrm{i}}$ representa o diâmetro médio da lesão no tempo ti, e $\mathrm{y}_{\mathrm{i}+1}$ é o diâmetro da lesão no tempo $t_{i+1}$. A incidência foi calculada 16 dias após a inoculação a partir do número de frutos sintomáticos em relação ao número total de frutos em cada tratamento.

No segundo experimento, os frutos foram imersos em: I) quitosana a $0,25 \%$; II) quitosana a $0,25 \%$ com glicerol a $0,75 \%$; III) quitosana a $0,25 \%$ combinada com glicerol a $0,75 \%$ e Tween 80 a $0,1 \%$; IV) quitosana a $0,25 \%$ com glicerol a $0,75 \%$, Tween 80 a $0,1 \%$ e estearato de magnésio a $0,3 \%$; V) quitosana a $0,25 \%$ com sorbitol a $0,75 \%(\mathrm{~m} / \mathrm{v})$; VI) quitosana a $0,25 \%$ com sorbitol a $0,75 \%$, Tween 80 a $0,1 \%$ e estearato de magnésio a $0,3 \%$. No terceiro, os frutos foram imersos em suspensões de quitosana a $0,25 \%$ ou a $0,5 \%$, combinadas ou não com Tween 80 a $0,1 \%$ ou com Tween 80 a $0,1 \%$ e estearato de magnésio a $0,1 \%$. No quarto experimento, os frutos foram imersos em suspensões de quitosana a $0,5 \%$ e Tween 80 a $0,1 \%$, combinadas com estearato de magnésio ou com oleato de sorbitano a 0,1 ou a $0,3 \%$ (v/v). A desinfestação superficial, o tempo de imersão dos frutos nas suspensões, a inoculação, a incubação e as avaliações da incidência e severidade da doença foram feitos de forma semelhante ao descrito anteriormente.

A análise de variância (ANOVA one way) e o teste de Tukey $(\alpha \leq 0,05)$ foram realizados para verificar a diferença entre as médias das variáveis analisadas nos experimentos pelo software Statistica 6.0 (STATSOFT).

A imersão dos frutos de macieira em suspensões de quitosana a 0,25 ou $0,5 \%$, contendo ou não adjuvantes, reduziu a severidade e a incidência do mofo azul em frutos tratados antes da inoculação. Esse resultado corrobora o observado por Romanazzi et al. (2002), os quais relataram efeito fungicida significativo de revestimentos de quitosana contra Botrytis cinerea em uva (Vitis vinifera L.). El Ghaouth et al. (1992) verificaram redução de 52 e $53 \%$ na incidência das podridões causadas por $B$. cinerea e Rhizopus stolonifer, respectivamente, em frutos de morango revestidos com quitosana a 1,0\%. Mazaro et al. (2008) observaram que o tratamento pré-colheita de morangueiro com quitosana reduziu a incidência de podridões nos frutos em pós-colheita. Outros autores verificaram maior efeito curativo do que protetor de 
suspensões de quitosana em uva 'Itália' contra $B$. cinerea (Camili et al., 2007).

No primeiro experimento, foi observado que a formulação contendo quitosana a $0,25 \%$ e glicerol a $0,25 \%$ reduziu a severidade do mofo azul em torno de $62 \%$ e a incidência em $53 \%$. Com o aumento da concentração de glicerol para $0,75 \%$, verificou-se uma redução de $79 \%$ na severidade e de $67 \%$ na incidência em relação à testemunha absoluta (frutos imersos em água destilada e inoculados). No entanto, esses tratamentos não diferiram estatisticamente daquele em que os frutos foram imersos em suspensão contendo apenas a quitosana (Tabela 1, Experimento 1). No segundo experimento, a suspensão contendo quitosana a $0,25 \%$ e glicerol a $0,75 \%$ reduziu a severidade da doença em torno de $60 \%$ em relação à testemunha. A adição apenas de sorbitol a $0,75 \%$ na suspensão de quitosana reduziu a severidade em $52 \%$, enquanto a incorporação de sorbitol a $0,75 \%$, estearato a $0,3 \%$ e Tween 80 a $0,1 \%$ reduziu a severidade em 37\% (Tabela 1, Experimento 2). Outros autores já haviam relatado o efeito do plastificante glicerol adicionado às suspensões de quitosana. Kim et al. (2006) observaram redução significativa na perda de peso e prolongamento da vida de prateleira de ovos revestidos com quitosana a 2, $0 \%(\mathrm{~m} / \mathrm{v})$ combinada com glicerol a 2, $0 \%(\mathrm{v} / \mathrm{v})$. Durango et al. (2006) demonstraram que o revestimento de quitosana a $1,5 \%$, contendo amido a $4,0 \%$ e glicerol a $2,0 \%$, foi uma alternativa viável para controlar a microbiota presente em cenouras minimamente processadas.

Testando-se duas concentrações de quitosana $(0,25$ e $0,5 \%)$ no mesmo experimento, notou-se aumento significativo no nível de controle da podridão de $P$. expansum com o aumento da concentração de quitosana (Tabela 1, Experimento 3). Este resultado está de acordo com os de Bautista-Baños et al. (2003), os quais demonstraram que a

TABELA 1 - Efeito preventivo da imersão de maçãs cv. Fuji em suspensões de quitosana associadas com adjuvantes no controle da podridão de Penicillium expansum. A imersão em água destilada foi utilizada como controle

\begin{tabular}{|c|c|c|c|}
\hline \multicolumn{4}{|c|}{ Experimento 1} \\
\hline \multicolumn{2}{|c|}{ Tratamento } & $\begin{array}{c}\text { Incidência } \\
(\%)\end{array}$ & $\begin{array}{l}\text { Severidade } \\
\text { (AACPD) }^{1}\end{array}$ \\
\hline I & Controle & 89 & $298,5 \pm 85,2 \mathrm{a}$ \\
\hline II & Q $0,25 \%$ & 59 & $130,9 \pm 25,7 \mathrm{~b}$ \\
\hline III & Q $0,25 \%+\mathrm{T} 0,1 \%$ & 41 & $163,5 \pm 141,3 a b$ \\
\hline IV & Q $0,25 \%+$ T $0,1 \%+$ E $0,1 \%$ & 53 & $179,8 \pm 43,3 \mathrm{ab}$ \\
\hline V & Q $0,25 \%+$ G $0,25 \%$ & 41 & $113,3 \pm 66,0 \mathrm{~b}$ \\
\hline VI & Q $0,25 \%+$ T $0,1 \%+$ G $0,25 \%$ & 71 & $141,1 \pm 47,7 \mathrm{ab}$ \\
\hline VII & Q $0,25 \%+$ G $0,75 \%$ & 29 & $62,3 \pm 48,7 b$ \\
\hline \multicolumn{4}{|c|}{ Experimento 2} \\
\hline I & Controle & 100 & $273,9 \pm 79,1 \mathrm{a}$ \\
\hline II & Q $0,25 \%$ & 53 & $137,0 \pm 32,2 \mathrm{ab}$ \\
\hline III & Q $0,25 \%+$ G $0,75 \%$ & 53 & $110,6 \pm 30,1 \mathrm{~b}$ \\
\hline IV & Q $0,25 \%+$ G $0,75 \%+$ T $0,1 \%$ & 69 & $87,8 \pm 78,8 b$ \\
\hline V & Q $0,25 \%+$ G $0,75 \%+$ T $0,1 \%+$ E $0,3 \%$ & 77 & $190,3 \pm 17,0 \mathrm{ab}$ \\
\hline VI & Q $0,25 \%+$ S $0,75 \%$ & 47 & $132,2 \pm 63,4 \mathrm{ab}$ \\
\hline VII & Q $0,25 \%+$ S $0,75 \%+$ T $0,1 \%+$ E $0,3 \%$ & 77 & $173,2 \pm 22,5 \mathrm{ab}$ \\
\hline \multicolumn{4}{|c|}{ Experimento 3} \\
\hline $\mathrm{I}$ & Controle & 94 & $361,9 \pm 19,8 \mathrm{a}$ \\
\hline II & Q $0,25 \%$ & 53 & $155,9 \pm 76,2 b c$ \\
\hline III & Q $0,5 \%$ & 59 & $89,6 \pm 33,7 \mathrm{c}$ \\
\hline IV & Q $0,25 \%+$ T $0,1 \%$ & 82 & $257,6 \pm 12,5 \mathrm{ab}$ \\
\hline V & Q $0,5 \%+$ T $0,1 \%$ & 65 & $105,4 \pm 56,9 \mathrm{c}$ \\
\hline VI & Q $0,25 \%+$ T $0,1 \%+$ E $0,1 \%$ & 53 & $137,9 \pm 75,1 \mathrm{bc}$ \\
\hline VII & $\mathrm{Q} 0,5 \%+\mathrm{T} 0,1 \%+\mathrm{E} 0,1 \%$ & 56 & $132,9 \pm 58,6 \mathrm{bc}$ \\
\hline \multicolumn{4}{|c|}{ Experimento 4} \\
\hline $\mathrm{I}$ & Controle & 100 & $188,8 \pm 56,1 \mathrm{a}$ \\
\hline II & Q $0,5 \%+$ T $0,1 \%$ & 55 & $52,9 \pm 9,7 \mathrm{~b}$ \\
\hline III & $\mathrm{Q} 0,5 \%+\mathrm{T} 0,1 \%+\mathrm{O} 0,1 \%$ & 35 & $33,8 \pm 31,9 \mathrm{bc}$ \\
\hline IV & $\mathrm{Q} 0,5 \%+\mathrm{T} 0,1 \%+\mathrm{O} 0,3 \%$ & 35 & $31,9 \pm 25,3 \mathrm{bc}$ \\
\hline $\mathrm{V}$ & Q $0,5 \%+$ T $0,1 \%+$ E $0,1 \%$ & 25 & $11,1 \pm 10,4 \mathrm{bc}$ \\
\hline VI & Q $0,5 \%+$ T $0,1 \%+$ E $0,3 \%$ & 25 & $4,4 \pm 6,4$ c \\
\hline
\end{tabular}

${ }^{1}$ Médias seguidas pela mesma letra não diferem entre si (Tukey a 5\%). AACPD: área abaixo da curva de progresso da doença; Q: quitosana; T: Tween 80; G: glicerol; S: sorbitol; O: oleato de sorbitano; E: estearato de magnésio. 
imersão de frutos de mamoeiro em suspensões de quitosana a 0,5 e 1,5\%, antes da inoculação com Colletotrichum gloeosporioides, reduziu significativamente a incidência da antracnose em $21 \%$ e $57 \%$, respectivamente.

A adição apenas de Tween à suspensão não melhorou a eficiência da quitosana (Tabela 1, Experimentos 1 e 3). No caso do tratamento quitosana e Tween 80 , houve maior incidência ( $82 \%$ ) de frutos com sintomas de podridão quando comparado à imersão dos frutos em suspensão contendo apenas o polissacarídeo a $0,25 \%$ (Tabela 1, Experimento 3). Choi et al. (2002) verificaram que a adição de $0,1 \%$ de Tween 80 aumentou a compatibilidade entre o revestimento de quitosana e a epiderme da maçã, diminuindo a tensão superficial do líquido e, assim, aumentando o coeficiente de espalhamento. Contudo, a adição de Tween 80 para reduzir a tensão superficial e promover maior molhabilidade e dispersão da suspensão, pode ter contribuído para facilitar a aderência e penetração dos esporos de $P$. expansum depositados sob os ferimentos no momento da inoculação dos frutos. Além disso, outros autores verificaram que filmes de amido de batata que continham apenas surfactantes (Tween 20, Span 80 e lecitina de soja) necessitavam da adição de glicerol para manter a sua integridade, devido à falta de interações fortes entre o surfactante e o biopolímero (Rodríguez et al., 2006).

A imersão das maçãs em formulação contendo estearato de magnésio a $0,3 \%$, Tween 80 a $0,1 \%$ e quitosana a $0,5 \%$ reduziu em $97,7 \%$ a severidade e em $75 \%$ a incidência do mofo azul, em relação aos frutos imersos em água destilada e inoculados (controle absoluto), diferindo também do tratamento em que os frutos foram imersos apenas na suspensão do polissacarídeo (Tabela 1, Experimento 4). Essa foi a melhor formulação encontrada para o tratamento preventivo dos frutos de macieira contra P. expansum. O estearato de magnésio, que é amplamente empregado na indústria farmacêutica como excipiente em comprimidos e cápsulas, pode ter interagido com as cargas positivas presentes nos grupos amino protonados $\left(-\mathrm{NH}_{3}^{+}\right)$ do polímero de quitosana, melhorando as características antimicrobianas do revestimento. As cargas positivas presentes na molécula de estearato de magnésio podem aumentar a repulsão eletrostática entre o polímero de quitosana e o próprio estearato. A repulsão eletrostática entre as cadeias poliméricas, devido à presença de grupos $-\mathrm{NH}_{3}^{+}$em meio ácido, foi relacionada ao aumento da solubilidade da quitosana em suspensão por Santos et al. (2003). Outros autores já haviam demonstrado que pode ocorrer interação entre o estearato de magnésio e fármacos, como, naproxeno (Botha \& Lötter, 1990), cetoprofeno (Mura et al., 1995) e fosinopril (Balestrieri et al., 1996). Quanto ao oleato de sorbitano, a severidade observada na imersão dos frutos em formulação contendo quitosana a $0,5 \%$ e oleato, nas duas concentrações avaliadas $(0,1$ ou $0,3 \%$ ), não diferiu estatisticamente da imersão em suspensão contendo apenas o polissacarídeo. Por outro lado, ocorreu uma redução na incidência da podridão, que foi de $35 \%$ em ambos os tratamentos contendo quitosana e oleato, contra $55 \%$ na suspensão contendo apenas quitosana (Tabela 1 , Experimento 4).

Um importante atributo da quitosana está associado às suas propriedades antifúngicas. Felipini \& Di Piero (2009) observaram que esse polissacarídeo reduziu o crescimento micelial e a germinação de esporos de Colletotrichum acutatum. Camili et al. (2007) relataram ocorrer alterações morfológicas nas hifas de $B$. cinerea após o tratamento com quitosana.

No presente trabalho, o revestimento formado pela imersão dos frutos em suspensões de quitosana pode ter atuado de forma direta servindo como barreira física entre o tecido do fruto e o esporo do fungo, contribuindo para reduzir a incidência e a severidade do mofo azul. Outros autores relacionaram o efeito do revestimento de quitosana sobre o crescimento de fitopatógenos com a redução na evolução de processos fisiológicos durante o armazenamento dos frutos tratados. Jianming et al. (1998) demonstraram que o tratamento com suspensão de quitosana a 1,2\% inibiu a germinação de esporos e o crescimento da hifa de $B$. cinerea sobre o pericarpo de maçãs da cv. "Jonagold". Segundo os autores, os frutos revestidos apresentaram menor ocorrência de fissuras ou rachaduras profundas, as quais poderiam tornar o tecido mais suscetível à invasão e colonização pelas hifas do fitopatógeno. Reduções na taxa de transpiração, na perda de umidade, na respiração, na produção de etileno e na retenção da firmeza são alguns resultados observados em banana e manga (Kittur et al., 2001), pêssegos ( $\mathrm{Li} \& \mathrm{Yu}, 2001$ ) e morangos (Mazaro et al., 2008) tratados com quitosana. Qiuping \& Wenshui (2007) verificaram ocorrer diminuição da taxa respiratória e da produção de etileno e poligalacturonase, aumento dos níveis de ácido ascórbico e sólidos solúveis totais, redução da perda de peso e maior permanência da coloração verde em cerejas da Índia (Ziziphus mauritiana cv. "Cuimi") revestidas com quitosana e 1-metilciclopropeno.

Pelos resultados obtidos, sugere-se que a redução da incidência e severidade do mofo azul em frutos de macieira, observada em frutos imersos nas formulações à base de quitosana, ocorreu em função da proteção conferida pelo revestimento ao tecido exposto pelo ferimento, dificultando a penetração e o estabelecimento do fitopatógeno. $O$ aumento da concentração de quitosana na suspensão proporcionou maior eficiência de controle e a formulação contendo quitosana a $0,5 \%$, estearato de magnésio a $0,3 \%$ e Tween 80 a $0,1 \%$ se mostrou a mais promissora para o controle do mofo azul em pós-colheita.

\section{REFERÊNCIAS BIBLIOGRÁFICAS}

Baert K, Devlieghere F, Bo L, Debevere J, Meulenaer BD (2008) The effect of inoculum size on the growth of Penicillium expansum in apples. Food Microbiology 25:212-217.

Balestrieri F, Magri AD, Magri AL, Marini D, Sacchini A (1996) Application of differential scanning calorimetry to the study of 
Quitosana e adjuvantes para o controle preventivo do mofo azul da macieira

drug-excipient compatibility. Thermochimica Acta 285:337-345.

Bautista-Baños S, López-Hernández M, Bosquez-Molina E, Wilson CL (2003) Effect of chitosan and plant extracts on growth of Colletotrichum gloeosporioides, anthracnose levels and quality of papaya fruit. Crop Protection 22:1087-1092.

Botha SA, Lötter AP (1990) Compatibility study between naproxen and tablet excipients using differential scanning calorimetry. Drug Development and Industrial Pharmacy 16:673-683.

Camili EC, Benato EA, Pascholati SF, Cia P (2007) Avaliação de quitosana, aplicada em pós-colheita, na proteção de uva 'Itália' contra Botrytis cinerea. Summa Phytopathologica 33:215-221.

Choi W, Park H, Anh D, Lee J, Lee C (2002) Wettability of chitosan coating solution on "Fuji" apple skin. Journal of Food Science 67:2668-2672.

Durango AM, Soares NFF, Andrade NJ (2006) Microbiological evaluation of an edible antimicrobial coating on minimally processed carrots. Food Control 17:336-341.

Dutta PK, Tripathi S, Mehrotra GK, Dutta J (2009) Perspectives for chitosan based antimicrobial films in food applications. Food Chemistry 114:1173-1182.

El Ghaouth A, Arul J, Grenier J, Asselin A (1992) Antifungal activity of chitosan on two postharvest pathogens of strawberry fruits. Phytopathology 82:398-402.

EMBRAPA. Produção Integrada de Maçã (PIM). Grade de Agroquímicos - Ciclo 2011/2012 http://www.cnpuv.embrapa.br/ tecnologias/pim/grade_agroquimicos.pdf

Felipini RB, Di Piero RM (2009) Redução da severidade da podridão-amarga em pós-colheita pela imersão de frutos em quitosana. Pesquisa Agropecuária Brasileira 44:1591-1597.

IBGE. Levantamento Sistemático da Produção Agrícola - outubro de 2011. http://www.ibge.gov.br/home/estatistica/indicadores/ agropecuaria/lspa/lspa_201110.pdf

Jianming D, Hiroshi G, Shuichi I (1998) Effects of chitosan coating on the storability and on the ultrastructural changes of "Jonagold" apple fruit in storage. Food Preservation Science 24:23-29.

Kim SH, No HK, Kim SD, Prinyawiwatkul W (2006) Effect of plasticizer concentration and solvent types on shelf-life of eggs coated with chitosan. Journal of Food Science 71:349-353.

Kittur FS, Saroja N, Habibunnisa, Tharanathan RN (2001) Polysaccharide-based composite coating formulations for shelflife extension of fresh banana and mango. European Food Research and Technology 213:306-311.

Li H, Yu T (2001) Effect of chitosan on incidence of brown rot, quality and physiological attributes of postharvest peach fruit. Journal of the Science of Food and Agriculture 81:269-274.

MAPA. Sistema de Agrotóxicos Fitossanitários (AGROFIT) http:// agrofit.agricultura.gov.br/agrofit_cons/principal_agrofit_cons (24 de novembro, 2011).

Mazaro SM, Deschamps C, May-de Mio LL, Biasi LA, Gouvea A, Sautter CK (2008) Comportamento pós-colheita de frutos de morangueiro após a aplicação pré-colheita de quitosana e acibenzolar-S-metil. Revista Brasileira de Fruticultura 30:185190.

Mura P, Manderioli A, Bramanti G, Furlanetto S, Pinzauti S (1995) Utilization of differential scanning calorimetry as a screening technique to determine the compatibility of ketoprofen with excipients. International Journal of Pharmaceutics 119:71-79.

Qiuping Z, Wenshui X (2007) Effect of 1-methylcyclopropene and/or chitosan coating treatments on storage life and quality maintenance of Indian jujube fruit. Food Science and Technology 40:404-411.

Rodríguez M, Osés J, Ziani K, Maté JI (2006) Combined effect of plasticizers and surfactants on the physical properties of starch based edible films. Food Research International 39:840-846.

Romanazzi G, Nigro F, Ippolito A, Di Venere D, Salerno M (2002) Effects of pre- and postharvest chitosan treatments to control storage gray mold of table grapes. Journal of Food Science 67:1862-1867.

Santos JE, Soares JP, Dockal ER, Campanha Filho SP, Cavalheiro ETG (2003) Caracterização de quitosanas comerciais de diferentes origens. Polímeros: Ciência e Tecnologia 13:242-249.

Shanner G, Finney RE (1977) The effect of nitrogen fertilization on the expression of slow mildewing resistance in know wheat. Phytopathology 67:1051-1056.

Sanhueza RMV (1996) Recomendações para o controle póscolheita das podridões de maçãs. Comunicado Técnico 21. Embrapa, Centro Nacional de Pesquisa de Uva e Vinho. pp. 1-4.

Sanhueza RMV (2004) Podridões de maçãs frigorificadas. In: Girardi CL (Ed.). Frutas do Brasil, Maçã: pós-colheita. Brasília DF. Embrapa Informação Tecnológica. pp. 35-44.

Zivanovic S, Chi S, Draughon AF (2005) Antimicrobial activity of chitosan films enriched with essential oils. Journal of Food Science 70:45-51.

TPP 241 - Recebido 27 January 2011 - Aceito 6 January 2012 Editor de Seção: Wagner Bettiol 